thy Haitian immigrants. $N$ Engl $J$ Med 1983;308: 125-9.

${ }^{8}$ Luft BJ, Conley F, Remington JS, et al. Outbreak of central nervous system toxoplasmosis in Western Europe and North America. Lancet 1983;i:781-3.

- Szychowska Z, Prandota-Schoepp A, Chabudzinska S. Rifampicin for pneumocystis carinii pneumonia. Lancet 1983; i: 935.

${ }^{10}$ Hughes WT, McNabb PC, Makres TD, Feldman S. Efficiency of trimethoprim and sulfamethoxazole in the prevention and treatment of pneumocystis carinii pneumonitis. Antimicrob Agents Chemother 1974;5:289-93.

"Oleske JM. Effects of antimicrobials on host defence mechanism. J Antimicrob Chemother 1984;13:413-5.

\section{Alcohol induced liver disease}

Dr Fleming's and Professor McGee's excellent review of alcohol induced liver disease $^{1}$ contained the following sentence: "The hepatocyte may be massively swollen, often being three times normal size." This could mean that the cell volume is three times normal, the cross sectional area is three times normal (therefore cell volume roughly five times normal), or the cell diameter is three times normal (therefore cell volume roughly 27 times normal). In this instance the photographs imply that the cell diameter is three times normal, but this inaccurate usage of the undefined term size is widespread throughout medical published work and may lead to serious misunderstandings.

\section{Bronglais General Hospital, Aberystwyth SY23 1ER}

\section{Reference \\ ${ }^{\prime}$ Fleming KA, McGee JO'D. Alcohol induced liver disease. J Clin Pathol 1984;37:721-33.}

Professor McGee replies as follows:

Dr Simpson makes a very cogent point in that the term size is open to misinterpretation when applied to a histological feature in a tissue section. When we stated that "The hepatocyte may be massively swollen, often being three times normal size" we did, in fact, mean that the maximum dimension of the two dimensional image of a hepatocyte was three times normal. We did not imply that size referred to diameter. Only circles have diameters; swollen hepatocytes are not circles and cannot be defined accurately by any standard geometric shape.

JO' D McGEE

Nuffield Department of Pathology, John Radcliffe Hospital, Headington, Oxford $O X 39 D U$
Value of factor VIII related antigen as a means of demonstrating extramedullary megakaryopoiesis

We were interested to read the brief report by Dr Crocker and Dr Smith on the value of factor VIII related antigen (VIIIRAg) as a marker for the immunohistological demonstration of megakaryocytes.' Since the original immunological localisation of VIIIRAg in platelets ${ }^{2}$ this antigen has been used as a marker for these and for megakaryocytes, ${ }^{3}$ but a word of warning is needed. Most commercial antisera of the type recommended by Dr Crocker and Dr Smith are prepared for relatively insensitive immunoprecipitation assays of VII-IRAg (von Willebrand factor antigen) and are not necessarily sufficiently specific or purposely absorbed for the much more sensitive immunohistological methods. ${ }^{4}$ Thus antisera may be contaminated with weak antibodies to fibronectin or other antigens and much more rigorous testing is needed to ensure monospecific antisera for immunohistological work. ${ }^{4}$ Use of monoclonal antibodies to VIIIRAg or antisera to specific platelet antigens such as $\beta$ thromboglobulin could circumvent these problems. Blocking controls using commercial "factor VIII" are not answers to this problem since even high potency therapeutic concentrates are crude mixtures of factor VIII complex (factor VIII coagulant and von Willebrand factor) with fibronectin, fibrinogen, and other proteins which, in fact, are their main constituents. In addition the difference between "factor VIII related antigen" and "factor VIII" is an important semantic problem which should be recognised by histologists. ${ }^{\circ}$

AL BLOOM
JC GIDDINGS
Department of Haematology,
University of Wales College of Medicine,
Heath Park,
Cardiff

\section{References}

' Crocker J, Smith PJ. Value of factor VIII related antigen as a means of demonstrating extramedullary megakaryopoiesis. $\mathrm{J}$ Clin Pathol 1984;37:834-5.

2 Bloom AL, Giddings JC, Wilks CJ. Factor VIII on the vascular intima: possible importance in haemostasis and thrombosis. Nature New Biology 1973;241:217-9.

${ }^{3}$ Innes DJ Jr, Mills SE, Walker GK Megakaryocyte leukaemia: identification utilising anti-factor VIII immunoperoxidase. Am J Clin Pathol 1982;77:107-10.
4 Giddings JC, Jarvis AL, Bloom AL. Differential localisation of porcine factor VIII related antigen (VIIIRAg) in vascular endothelium and endothelial cells in culture. Thromb Res 1983;29:299-312.

${ }^{5}$ Giddings JC. The purification of factor VIII and IX and production of specific antisera. In: Bloom AL, ed. The hemophilias. Edinburgh: Churchill Livingstone, 1982:51-82.

- Bloom AL. The mysteries of the factor VIII molecule. In: Woolf $\mathrm{N}$, ed. Biology and pathology of the vessel wall. Eastbourne: Praeger, 1983:129-46.

\section{Book Reviews}

Aluminium Analysis In Biological Fluids. Ed MR Wills and J Savory. (Pp 132; $\$ 25.00$.) University of Virginia Press, USA. 1983.

These are the proceedings of a conference held at the University of Virginia in June 1983. To some, aluminium analysis might seem to be a rather esoteric topic for a meeting and the proceedings likely to be of little interest to pathologists. But even though the clinical importance of aluminium has been recognised for barely ten years the measurement of aluminium in water supplies, biological fluids, and tissues has become an important procedure in many clinical laboratories. Thus the clinical and toxicological importance of aluminium is now well established and should be of general interest to all pathologists.

Aluminium is the third most abundant element in the earth's crust and it is widely distributed in nature. In the healthy adult, the body-burden of aluminium is less than $300 \mathrm{mg}$. However, in patients with chronic renal failure there is unequivocal evidence of a general increase in the body burden of aluminium. In such patients aluminium is strongly implicated in the aetiology of encephalopathy, microcytic anaemia, and osteomalacia. It may be implicated also in the pathogenesis of Alzheimer's disease and some other neurological disorders, although here the evidence is less certain.

In their foreword to the conference proceedings the editors state that their purpose was to review the "state of the art" in analytical methods for the assay of aluminium in biological material. In this reviewer's opinion they have succeeded admirably in the task. The volume contains 14 papers on various aspects of analysis from acknowledged experts in the field. The variety of techniques reviewed includes electrothermal (flameless) atomic absorption spectrophotometry, neutron activation analysis, scanning electron mic- 